\title{
Effect of various levels of isoflavone aglycone-enriched fermented soybean meal on redox status, serum hormones and milk quality in ewes
}

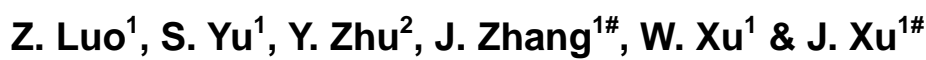 \\ ${ }^{1}$ School of Agriculture and Biology, Shanghai Jiao Tong University, Shanghai Key Laboratory of Veterinary \\ Biotechnology, 200240, Shanghai, China. \\ ${ }^{2}$ Chongming Animal Disease Control Centre, 202150, Shanghai, China.
}

(Received 29 November 2017; Accepted 13 June 2018; First published online 7 August 2018)

Copyright resides with the authors in terms of the Creative Commons Attribution 4.0 South African Licence.
See: http://creativecommons.org/licenses/by/4.0/za
Condition of use: The user may copy, distribute, transmit and adapt the work, but must recognise the authors and the South African
Journal of Animal Science.

\begin{abstract}
The study investigated the effects of various levels of isoflavone aglycone-enriched fermented soybean meal (FSBM) on the redox status, serum hormones and milk quality of ewes from late pregnancy to early lactation. Twenty Chongming White ewes were chosen and divided into four treatment groups $(n=5)$ : basal diet without FSBM (CON); basal diet with 2\% (FSBM2); 4\% (FSBM4); and 6\% FSBM (FSBM6) replacing equal amounts of soybean meal (SBM). At parturition, maternal serum, the placenta and colostrum were collected. At day 21 of lactation, maternal serum and milk were collected. Results showed that, compared with CON, feeding ewes with FSBM6 reduced the concentrations of hydrogen peroxide $\left(\mathrm{H}_{2} \mathrm{O}_{2}\right)$ and 8-hydroxy-2-deoxyguanosine (8-OHdG), and increased the activity of superoxide dismutase (SOD) and total antioxidant capacity (T-AOC) concentration in the placenta. At parturition and day 21 of lactation, the serum SOD activity and T-AOC concentration in FSBM4 and FSBM6 were higher than those in CON. Furthermore, the concentration of serum 8-iso prostaglandin (8-ISO-PGF2 $\alpha$ ) was markedly lower in FSBM6 than in CON. Serum prolactin (PRL), insulin-like growth factor 1 (IGF-1) and epidermal growth factor (EGF) concentrations were increased in FSBM4 and FSBM6 compared with CON. PRL concentration was increased in FSBM2. FSBM4 increased the levels of fat, protein, lactose, IgA, IgG and IgM in colostrum and milk. In conclusion, feeding ewes with FSBM from late pregnancy to early lactation seemed to increase maternal and placental anti-oxidative capacity, and improve serum hormones and milk quality. Considered overall, the level of $4 \%$ supplementation is recommended.
\end{abstract}

Keywords: Milk contents, oxidative stress, placenta, serum parameters

\#Corresponding authors: zhangjing224@sjtu.edu.cn, jxxu1962@sjtu.edu.cn

\section{Introduction}

Soy isoflavones, which are found predominantly in soybeans, have been shown to have many benefits, such as the prevention of cardiovascular disease and cancer, and antidiabetic properties (Yuan et al., 2007). Most isoflavones in soybean meal are glucosides, which are poorly absorbed in monogastric animals (RuizLarrea et al., 1997). However, microorganisms can hydrolyse isoflavone glycosides to aglycones. Part of these hydrolysed isoflavones is readily absorbed from the rumen of sheep, which is suggested to resemble, qualitatively, that of cattle (Lundh, 1995). Nonetheless, ewes are more sensitive to isoflavones than cows. Excessive consumption of these phytoestrogens may reduce prolificacy in reproductive ewes and mammary fluid production in nulliparous ewes (Adams, 1995; Taponen et al., 2010). Fermentation of soybean meal can not only eliminates anti-nutritional factors, but can transform glucosides into active aglycones, which exhibit superior anti-inflammatory, antioxidant activity and bioavailability characteristics (Murakami et al., 1984; Champagne et al., 2010). Previously, the percentage of isoflavone aglycones was reported to reach $85.6 \%$ from microbial solid-state fermentation and free radical scavenging capability increased in vitro (Yang \& Xu, 2013; Yin et al., 2015).

In domestic animals pregnancy and early lactation periods are stressful events that are characterized by higher nutrient requirements and oxygen consumption, which have been reported to be associated with 
an increase in the production of reactive oxygen species (ROS) and oxidative stress (Castillo et al., 2005; Berchieri-Ronchi et al., 2011; Mutinati et al., 2013). It has been reported that serum hydrogen peroxide $\left(\mathrm{H}_{2} \mathrm{O}_{2}\right)$, lipid peroxide malondialdehyde (MDA) and protein carbonyl concentrations increased at parturition and at day 21 of lactation in ewes compared with early gestation (Yu et al., 2017). Disruption of the antioxidant system leads to oxidative stress, which is involved in pregnancy complications, causing foetal mortality and morbidity (Sugino et al., 2007). Maternal nutrition plays a critical role in foetal growth and in modifying the intrauterine condition during late gestation (Min et al., 2009). The placenta constitutes the maternal-foetal interface and supports the normal growth and development of the foetus (Sferruzzi-Perri \& Camm, 2016). Antioxidants such as daidzein (aglycones) have been suggested to be able to cross the placenta and can potentially be endocrine modulators during gestation (Degen et al., 2002). On the other hand, mammary gland development and milk composition influence the postnatal growth of lambs positively. Until now, studies about the effect of fermented soybean meal (FSBM) on the biological properties of milk and maternal-placental health in ewes have not been described. Therefore, in accordance with a preliminary experiment (unpublished data), the present study was designed to replace $2 \%, 4 \%$ and $6 \%$ SBM with FSBM, respectively, and evaluate the effect of this on the maternal-placental redox status and milk quality of ewes from late pregnancy to early lactation.

\section{Materials and Methods}

The experiment protocol was in accordance with the guidelines of Shanghai Jiao Tong University Institutional Animal Care and Use Committee.

A compound probiotic (lot number 120815), including Lactobacillus, Saccharomyces and Bacillus subtilis, was purchased from a commercial company (Shanghai Chuangbo Ecological Engineering Co. Ltd, Shanghai, China), and contained active bacteria numbers of $\geq 50 \times 10^{8} \mathrm{CFU} / \mathrm{mL}$ and Lactobacillus numbers of $\geq 12 \times 10^{8} \mathrm{CFU} / \mathrm{mL}$. The technical parameters of solid-state fermented soybean meal were according to Patent 201310557000 (Xu et al., 2013). Briefly, the ratios of pulverized soybean meal (20 mesh), water and compound probiotics were $55: 40: 5$, mixed and sealed, and fermented in an incubator at $35{ }^{\circ} \mathrm{C}$ for 72 hours. The FSBM contained isoflavone aglycones, namely $392 \mathrm{mg} / \mathrm{kg}$ of daidzein, $130 \mathrm{mg} / \mathrm{kg}$ of glycitein, $1211 \mu \mathrm{g} / \mathrm{kg}$ of genistein and $2025 \mathrm{mg} / \mathrm{kg}$ of total isoflavones. According to the analytical methods of Yin et al. (2015), the percentage of isoflavone aglycones to total isoflavones reached $85.6 \%$.

The experiment was carried out at Chongming Cultivation Base (Chongming District, Shanghai, China). A total of 20 Chongming White ewes with similar bodyweight (BW) (about $36 \mathrm{~kg}$ ) at day 100 of gestation was chosen, checked for the number of foetuses, parity and previous lactation milk yield, and then allocated randomly into four groups of five ewes per treatment: i) CON, a control group fed a basal diet without FSBM; ii) FSBM2, basal diet with 2\% FSBM replacing 2\% SBM; iii) FSBM4, basal diet with 4\% FSBM replacing 4\% SBM; and iv) FSBM6, basal diet with 6\% FSBM replacing 6\% SBM. The levels of FSBM were selected according to a preliminary experiment (unpublished data) of the authors. All ewes were fed twice daily (at 9:00 and 14:00). Feed allocation was adjusted weekly according to BW and physiological status (pregnancy and lactation) (Table 1). The dietary compositions were analysed according to the methods of the Association of Official Analytical Chemists (AOAC, 1990).

The experiment was conducted from day 100 of gestation to day 21 of lactation. Water was freely available to ewes throughout the period. At day $150 \pm 1$ of gestation, the lambing process was monitored and placental tissues $(10 \mathrm{~g})$ were dissected from the central region (2 to $4 \mathrm{~cm}$ from the cord insertion point) within 15 minutes of being discharged, washed with $0.9 \%$ cold saline solution, placed in tubes and frozen at $-80{ }^{\circ} \mathrm{C}$ for analysis of oxidative stress parameters. The lambs were kept with their mothers and allowed to suckle. Growth performances such as BW of ewes and lamb were measured and recorded (Table 2). Lambs were allowed to take in colostrum 1-2 hours after being born. On postnatal days 1 and 2, lambs could suckle milk ad libitum. Lambs had free access to water throughout lactation, but not access to creep feed until postnatal day 4. At parturition and at day 21 of lactation, fasting blood samples $(10 \mathrm{~mL})$ from the jugular vein were collected through vacutainer glass tubes from all the ewes. Serum samples were obtained by centrifugation at $3000 \times \mathrm{g}$ for $15 \mathrm{~min}$ and stored at $-80{ }^{\circ} \mathrm{C}$ until analysis for oxidative stress parameters and hormone concentrations were performed. After birth of the lambs, colostrum $(30 \mathrm{~mL})$ was taken from the same nipples of each ewe. Milk $(30 \mathrm{~mL})$ was collected at day 21 of lactation before morning feeding. Ten $\mathrm{mL}$ of samples were centrifuged at $3000 \times \mathrm{g}$ for $20 \mathrm{~min}$ at $4{ }^{\circ} \mathrm{C}$. The supernatant was collected and frozen at $-80{ }^{\circ} \mathrm{C}$ for immunoglobulin analysis. The remaining samples were stored at $-80^{\circ} \mathrm{C}$ for nutrient content analyses. 
Table 1 Composition and nutrient levels of experimental diets from day 100 of gestation to day 21 of lactation

\begin{tabular}{|c|c|c|c|c|}
\hline \multirow{2}{*}{ Item } & \multicolumn{4}{|c|}{ Treatments $^{1}$} \\
\hline & $\mathrm{CON}^{3}$ & FSBM2 & FSBM4 & FSBM6 \\
\hline \multicolumn{5}{|l|}{ Ingredient, \% } \\
\hline Corn stalk meal & 40.2 & 40.2 & 40.2 & 40.2 \\
\hline Soybean stalk meal & 30.0 & 30.0 & 30.0 & 30.0 \\
\hline Corn & 17.0 & 17.0 & 17.0 & 17.0 \\
\hline Soybean meal & 11.0 & 9.0 & 7.0 & 5.0 \\
\hline Fermented soybean meal $^{1}$ & 0.0 & 2.0 & 4.0 & 6.0 \\
\hline Salt & 0.3 & 0.3 & 0.3 & 0.3 \\
\hline Premix $^{2}$ & 1.5 & 1.5 & 1.5 & 1.5 \\
\hline Total & 100 & 100 & 100 & 100 \\
\hline \multicolumn{5}{|l|}{ Nutrient ${ }^{2}$ levels } \\
\hline DM, \% & 86.5 & 86.5 & 86.5 & 86.5 \\
\hline $\mathrm{DE}, \mathrm{kJ} / \mathrm{g}$ & 14.8 & 14.8 & 14.7 & 14.7 \\
\hline $\mathrm{CP}, \%$ & 13.5 & 13.7 & 13.8 & 13.9 \\
\hline EE, \% & 1.5 & 1.5 & 1.5 & 1.4 \\
\hline NDF, \% & 49.9 & 49.9 & 49.8 & 49.8 \\
\hline ADF, $\%$ & 33.6 & 33.6 & 33.5 & 33.5 \\
\hline Calcium, \% & 0.6 & 0.6 & 0.5 & 0.5 \\
\hline Phosphorus, \% & 0.2 & 0.2 & 0.2 & 0.2 \\
\hline \multicolumn{5}{|c|}{ 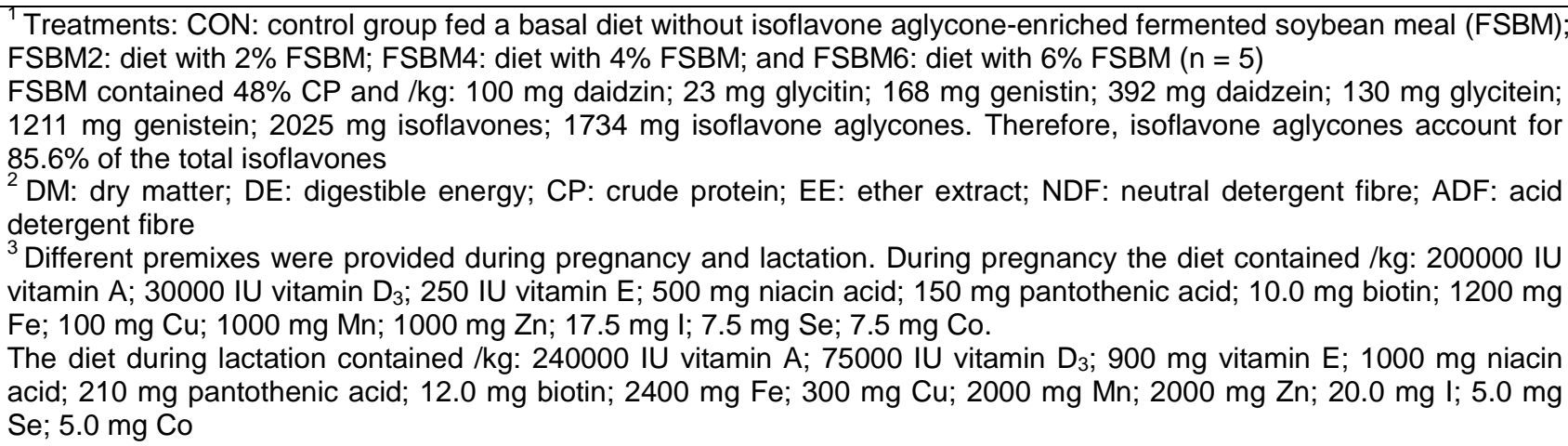 } \\
\hline
\end{tabular}

Placental tissues were homogenized in $0.9 \%$ cold saline solution. The supernatants were collected by centrifugation at $3000 \times \mathrm{g}$ at $4{ }^{\circ} \mathrm{C}$ for $10 \mathrm{~min}$. Protein concentration was measured according to the instructions of the bicinchoninic acid (BCA) protein assay kit (P0010, Beyotime Biotech, Shanghai, China). The concentrations of $\mathrm{H}_{2} \mathrm{O}_{2}$, total antioxidant capacity (T-AOC) and malondialdehyde (MDA), and superoxide dismutase (SOD, EC1.15.1.1) activity in the placenta and serum were measured with commercial kits (Nanjing Jiancheng Bioengineering Institute, Nanjing, China), according to the manufacturer's instructions. The values in the placental tissues and serum were expressed as unit $/ \mathrm{mg}$ protein and unit/mL, respectively.

The concentrations of 8-iso prostaglandin (8-ISO-PGF2 $\alpha$ ) and 8-hydroxy-2-deoxyguanosine (8-OHdG) in the serum and placenta, the concentrations of prolactin (PRL), insulin-like growth factor 1 (IGF-1) and epidermal growth factor (EGF) in the serum (Nanjing Jiancheng Bioengineering Institute, Nanjing, China), and the concentrations of $\operatorname{Ig} \mathrm{A}$, IgM, IgG in milk (Shanghai Yuanye Bioengineering Institute, Shanghai, China) were determined with commercial ELISA kits (Luo et al., 2016). Briefly, the plates were coated with the corresponding antibodies. After stabilizing the kits for 0.5 hours at room temperature, samples were added to each well, then biotinylated $A b$ working solution $(50 \mu \mathrm{L})$ was included, and the samples were incubated for 1 hour at $37^{\circ} \mathrm{C}$. Then the wells were drained and washed five times with a washing solution. Horseradish peroxidase working solution was added to each well and incubated 1 hour at $37^{\circ} \mathrm{C}$. Then the wells were washed again five times and dried. Chromogenic solutions $A(50 \mu \mathrm{L})$ and $B(50 \mu \mathrm{L})$ were included in each 
well successively and incubated for $10 \mathrm{~min}$ at $37^{\circ} \mathrm{C}$ in the dark. Finally, the stop solution $(50 \mu \mathrm{L})$ was added to stop the reaction. Absorbance values were then read in a 96-well plate reader (BioTek Synergy 2, USA) at $450 \mathrm{~nm}$ within $10 \mathrm{~min}$. The values were calculated according to a standard curve.

Table 2 Effect of isoflavone aglycones-enriched fermented soybean meal (FSBM) on ewes' growth performance from late gestation to early lactation

\begin{tabular}{|c|c|c|c|c|}
\hline \multirow{2}{*}{ Item $^{1}$} & \multicolumn{4}{|c|}{ Treatments $^{2}$} \\
\hline & CON & FSBM2 & FSBM4 & FSBM6 \\
\hline \multicolumn{5}{|l|}{ Parturition day, kg } \\
\hline Ewes BW ${ }^{1}$ & $33.9 \pm 4.62$ & $33.6 \pm 5.31$ & $28.1 \pm 6.07$ & $34.8 \pm 3.75$ \\
\hline Litter BW & $4.01^{b} \pm 1.03$ & $5.31^{a} \pm 0.52$ & $3.62^{b} \pm 0.66$ & $5.39^{\mathrm{a}} \pm 1.24$ \\
\hline Mean lamb BW & $2.23^{a} \pm 0.33$ & $1.77^{\mathrm{b}} \pm 0.31$ & $1.81^{b} \pm 0.40$ & $1.96^{\mathrm{ab}} \pm 0.35$ \\
\hline Litter size, $\mathrm{n}$ & $1.80^{b} \pm 0.45$ & $3.00^{a} \pm 0.00$ & $2.00^{b} \pm 0.00$ & $2.75^{\mathrm{a}} \pm 0.96$ \\
\hline \multicolumn{5}{|c|}{ D 21 of lactation, $\mathbf{k g}$} \\
\hline Ewes BW & $35.2 \pm 5.93$ & $34.8 \pm 6.13$ & $28.2 \pm 4.97$ & $34.0 \pm 2.58$ \\
\hline Litter BW & $11.6^{b} \pm 5.79$ & $12.4^{b} \pm 3.59$ & $11.3^{b} \pm 1.30$ & $17.7^{\mathrm{a}} \pm 1.68$ \\
\hline Mean lamb BW & $7.26^{a} \pm 1.98$ & $5.41^{b} \pm 1.89$ & $5.63^{b} \pm 0.69$ & $7.09^{a} \pm 1.20$ \\
\hline Litter size, $\mathrm{n}$ & $1.60^{b} \pm 0.55$ & $2.20^{\mathrm{ab}} \pm 0.84$ & $2.00^{\mathrm{ab}} \pm 0.00$ & $2.50^{a} \pm 0.58$ \\
\hline \multicolumn{5}{|l|}{ Daily gain, g/d } \\
\hline Ewes BW & $0.03 \pm 0.09$ & $0.02 \pm 0.05$ & $0.00 \pm 0.05$ & $-0.02 \pm 0.05$ \\
\hline Litter BW & $0.17^{\mathrm{b}} \pm 0.11$ & $0.18^{\mathrm{ab}} \pm 0.06$ & $0.16^{\mathrm{ab}} \pm 0.03$ & $0.27^{\mathrm{a}} \pm 0.02$ \\
\hline
\end{tabular}

Nutrient composition such as level of fat, total protein, lactose and non-fat solid (SNF) in milk samples was determined with a milk composition analyser (MilkoScan FT1, Foss, Sweden).

Data were analysed with SPSS 17.0 (SPSS Inc., USA). Results were expressed as mean \pm SD. Comparisons between these groups were analysed with one-way analysis of variance (ANOVA), followed by least significant difference test. $P<0.05$ was used to assess significance.

\section{Results}

The effects of FSBM on placental oxidative stress parameters in ewes are shown in Table 3. Compared with CON and FSBM2, the concentration of placental free radical $\mathrm{H}_{2} \mathrm{O}_{2}$ was decreased $(P<0.05)$ in FSBM6, but not in FSBM4. Feeding ewes with FSBM2 and FSBM6 increased $(P<0.05)$ the activity of SOD in the placenta compared with CON. The concentration of T-AOC was $(P<0.05)$ higher in FSBM4 and FSBM6 than in CON. The results of oxidative injury parameters showed that MDA and 8-ISO-PGF2 $\alpha$ were not significantly $(P>0.05)$ different among groups, while the concentration of 8-OHdG was decreased $(P$ $<0.05$ ) in FSBM 2, FSBM4 and FSBM6 compared with that in CON.

The effects of FSBM on serum oxidative stress parameters in ewes are shown in Table 3 . At parturition, compared with $\mathrm{CON}$, the concentration of serum free radical $\mathrm{H}_{2} \mathrm{O}_{2}$ was decreased $(P<0.05)$ in FSBM6. Compared with CON and FSBM2, the activity SOD and serum concentrations of T-AOC were higher $(P<0.05)$ in FSBM6. The activity of SOD and T-AOC concentration also increased $(P<0.05)$ in FSBM4, compared with CON. Feeding ewes with FSBM did not influence $(P>0.05)$ serum MDA and 8-OHdG concentration, but the serum concentration of 8 -ISO-PGF2 $\alpha$ decreased $(P<0.05)$ markedly in FSBM6 compared with CON. At day 21 of lactation, serum $\mathrm{H}_{2} \mathrm{O}_{2}$ and MDA concentrations were not markedly different $(P>0.05)$ among the treatments. Feeding ewes with FSBM4 and FSBM6 $(P<0.05)$ improved the activity of SOD and concentration of T-AOC compared with CON. In addition, the activity of SOD was increased $(P$ $<0.05)$ in FSBM2 compared with CON. The concentration of 8-ISO-PGF2 $\alpha$ was decreased $(P<0.05)$ 
markedly in FSBM6 compared with CON and FSBM2. The concentration of 8-OHdG decreased $(P<0.05)$ in FSBM6 compared with the other three groups.

Table 3 Effect of isoflavone aglycone-enriched fermented soybean meal (FSBM) on oxidative stress parameters in placenta and serum of ewes

\begin{tabular}{|c|c|c|c|c|c|c|c|}
\hline \multirow{2}{*}{ Item $^{1}$} & \multicolumn{4}{|c|}{ Treatments $^{2}$} & \multicolumn{3}{|c|}{$P$ value } \\
\hline & CON & FSBM2 & FSBM4 & FSBM6 & $L^{3}$ & $\mathbf{Q}$ & C \\
\hline \multicolumn{8}{|l|}{ Placenta } \\
\hline $\mathrm{H}_{2} \mathrm{O}_{2}, \mathrm{mmol} / \mathrm{g}$ prot & $122.7^{\mathrm{a}} \pm 36.04$ & $122.7^{\mathrm{a}} \pm 13.01$ & $106.4^{\mathrm{ab}} \pm 19.87$ & $79.9^{b} \pm 19.34$ & 0.020 & 0.274 & 0.904 \\
\hline SOD, U/mg prot & $108.6^{c} \pm 7.30$ & $137.0^{\mathrm{ab}} \pm 22.67$ & $127.8^{\mathrm{bc}} \pm 10.11$ & $153.9^{a} \pm 13.84$ & 0.009 & 0.891 & 0.062 \\
\hline T-AOC, U/mg prot & $13.93^{b} \pm 2.35$ & $22.38^{\mathrm{ab}} \pm 3.26$ & $23.26^{a} \pm 6.18$ & $23.40^{\mathrm{a}} \pm 7.67$ & 0.049 & 0.175 & 0.593 \\
\hline MDA, nmol/mg prot & $200.5 \pm 38.42$ & $184.5 \pm 52.92$ & $174.7 \pm 49.45$ & $129.6 \pm 43.75$ & 0.074 & 0.568 & 0.710 \\
\hline 8-ISO-PGF2a, pg/mg prot & $66.0 \pm 4.04$ & $63.4 \pm 17.60$ & $60.8 \pm 2.12$ & $56.7 \pm 7.51$ & 0.304 & 0.898 & 0.905 \\
\hline 8-OHdG, ng/mg prot & $33.2^{\mathrm{a}} \pm 0.59$ & $26.7^{\mathrm{b}} \pm 2.26$ & $24.4^{\mathrm{b}} \pm 3.22$ & $22.6^{\mathrm{b}} \pm 3.94$ & 0.000 & 0.153 & 0.584 \\
\hline \multicolumn{8}{|l|}{ Serum, parturition day } \\
\hline $\mathrm{H}_{2} \mathrm{O}_{2}, \mathrm{mmol} / \mathrm{L}$ & $13.12^{\mathrm{a}} \pm 7.43$ & $11.36^{\mathrm{ab}} \pm 2.90$ & $7.93^{\mathrm{ab}} \pm 3.27$ & $6.59^{b} \pm 1.70$ & 0.029 & 0.922 & 0.685 \\
\hline $\mathrm{SOD}, \mathrm{U} / \mathrm{mL}$ & $62.0^{c} \pm 0.96$ & $66.0^{\mathrm{bc}} \pm 3.70$ & $71.1^{\mathrm{ab}} \pm 4.15$ & $75.6^{a} \pm 7.74$ & 0.004 & 0.938 & 0.904 \\
\hline T-AOC, U/mL & $1.63^{c} \pm 0.56$ & $2.42^{\mathrm{bc}} \pm 0.32$ & $3.63^{\mathrm{ab}} \pm 1.91$ & $4.16^{a} \pm 0.41$ & 0.001 & 0.799 & 0.616 \\
\hline $\mathrm{MDA}, \mathrm{nmol} / \mathrm{mL}$ & $24.5 \pm 8.91$ & $16.5 \pm 8.40$ & $15.0 \pm 6.37$ & $17.5 \pm 4.56$ & 0.171 & 0.145 & 0.869 \\
\hline 8-ISO-PGF2 $\alpha, \mathrm{pg} / \mathrm{mL}$ & $65.4^{a} \pm 10.96$ & $57.2^{\mathrm{a}} \pm 8.64$ & $53.1^{\mathrm{ab}} \pm 10.73$ & $42.2^{\mathrm{b}} \pm 9.17$ & 0.003 & 0.769 & 0.597 \\
\hline 8-OHdG, ng/mL & $3.77 \pm 1.98$ & $2.89 \pm 1.28$ & $2.74 \pm 1.16$ & $2.23 \pm 1.06$ & 0.143 & 0.779 & 0.700 \\
\hline \multicolumn{8}{|l|}{ Serum, day 21 of lactation } \\
\hline $\mathrm{H}_{2} \mathrm{O}_{2}, \mathrm{mmol} / \mathrm{L}$ & $7.90 \pm 3.13$ & $6.68 \pm 2.37$ & $6.57 \pm 2.10$ & $7.06 \pm 2.22$ & 0.961 & 0.481 & 0.652 \\
\hline $\mathrm{SOD}, \mathrm{U} / \mathrm{mL}$ & $65.2 \pm 2.83$ & $68.2 \pm 7.53$ & $72.3 \pm 8.28$ & $73.7 \pm 7.16$ & 0.056 & 0.081 & 0.794 \\
\hline $\mathrm{T}$-AOC, U/mL & $2.05^{b} \pm 0.38$ & $3.45^{\mathrm{ab}} \pm 1.07$ & $4.54^{a} \pm 1.31$ & $4.72^{\mathrm{a}} \pm 1.68$ & 0.002 & 0.272 & 0.806 \\
\hline $\mathrm{MDA}, \mathrm{nmol} / \mathrm{mL}$ & $21.00 \pm 6.75$ & $20.00 \pm 6.85$ & $19.00 \pm 5.18$ & $20.00 \pm 2.04$ & 0.745 & 0.710 & 0.864 \\
\hline 8-ISO-PG2a, pg/mL & $66.4^{a} \pm 10.77$ & $56.1^{\mathrm{ab}} \pm 4.26$ & $47.3^{\mathrm{bc}} \pm 9.47$ & $35.2^{\mathrm{c}} \pm 17.80$ & 0.001 & 0.864 & 0.836 \\
\hline 8-OHdG, ng/mL & $3.74^{\mathrm{a}} \pm 1.41$ & $3.06^{a} \pm 1.25$ & $2.86^{\mathrm{a}} \pm 0.90$ & $1.81^{\mathrm{b}} \pm 1.30$ & 0.042 & 0.753 & 0.597 \\
\hline
\end{tabular}

${ }^{a, b, c}$ Means with different superscripts within the same row are statistically different $(P<0.05)$

${ }^{1} \mathrm{H}_{2} \mathrm{O}_{2}$ : hydrogen peroxide; SOD: superoxide dismutase; T-AOC: total antioxidant capacity; MDA: malondialdehyde; 8ISO-PGF2 $\alpha$ : 8-iso-prostaglandin; 8-OHdG: 8-hydroxy-2-deoxyguanosine

${ }^{2}$ Treatment: CON: control group fed a basal diet without FSBM $(n=5)$; FSBM2: diet with 2\% FSBM $(n=5)$; FSBM4: diet with 4\% FSBM $(n=5)$; FSBM6: diet with 6\% FSBM $(n=4)$

One ewe died because of difficult labour in FSBM6 at parturition

${ }^{3}$ Linear (L), quadratic (Q) or cubic (C) effect of FSBM

The effects of FSBM on serum PRL, IGF-1 and EGF of ewes are presented in Table 4. At parturition, the concentrations of PRL, IGF-1 and EGF were higher $(P<0.05)$ in FSBM than in CON. In addition, the concentration of PRL was greater $(P<0.05)$ in FSBM4 than in FSBM2 and FSBM6. On day 21 of lactation, compared with CON, the concentrations of PRL in FSBM2 and FSBM4 increased markedly $(P<0.05)$, but not in FSBM6 $(P>0.05)$. Feeding ewes with FSBM increased $(P<0.05)$ the serum IGF-1 and EGF concentrations compared with CON. Furthermore, serum IGF-1 increased $(P<0.05)$ more in FSBM4 and FSBM6 than in FSBM2.

The effect of FSBM on the colostrum and milk composition of ewes is presented in Table 5. In the colostrum, the levels of fat, protein, lactose and SNF were higher $(P<0.05)$ in FSBM groups than those in the CON. Moreover, the level of fat increased significantly more $(P<0.05)$ in FSBM4 than in FSBM2 and FSBM6. In the milk, compared with the CON, feeding FSBM $(P<0.05)$ increased the levels of fat, protein and lactose. In addition, compared with FSBM2 and FSBM6, the level of protein was increased $(P<0.05)$ in FSBM4. No difference $(P>0.05)$ in SNF was observed among the four groups. 
Table 4 Effect of isoflavone aglycone-enriched fermented soybean meal (FSBM) on concentrations of serum hormones in ewes

\begin{tabular}{lccccccc}
\hline & \multicolumn{9}{c}{ Treatments $^{2}$} & \multicolumn{2}{c}{$\boldsymbol{P}^{2}$ value } \\
\cline { 2 - 8 } Item $^{1}$ & CON $^{2}$ & FSBM2 & FSBM4 & FSBM6 & $\mathbf{L}^{3}$ & Q & C \\
\hline Parturition day & & & & & & & \\
PRL, ng/mL & $28.3^{\mathrm{c}} \pm 2.31$ & $34.9^{\mathrm{b}} \pm 1.94$ & $43.2^{\mathrm{a}} \pm 2.10$ & $33.3^{\mathrm{b}} \pm 0.63$ & 0.000 & 0.000 & 0.000 \\
IGF-1, ng/mL & $80.2^{\mathrm{b}} \pm 3.61$ & $139.0^{\mathrm{a}} \pm 13.33$ & $153.6^{\mathrm{a}} \pm 13.74$ & $145.8^{\mathrm{a}} \pm 11.32$ & 0.000 & 0.000 & 0.351 \\
EGF, ng/L & $212.5^{\mathrm{b}} \pm 17.40$ & $252.5^{\mathrm{a}} \pm 24.08$ & $265.7^{\mathrm{a}} \pm 10.63$ & $272.0^{\mathrm{a}} \pm 25.53$ & 0.000 & 0.086 & 0.627 \\
D 21 of lactation & & & & & & & \\
PRL, ng/mL & $32.5^{\mathrm{c}} \pm 2.29$ & $40.9^{\mathrm{b}} \pm 2.79$ & $49.0^{\mathrm{a}} \pm 3.65$ & $34.8^{\mathrm{c}} \pm 4.16$ & 0.045 & 0.000 & 0.004 \\
IGF-1, ng/mL & $88.9^{\mathrm{c}} \pm 4.47$ & $150.6^{\mathrm{b}} \pm 10.07$ & $171.0^{\mathrm{a}} \pm 5.17$ & $172.4^{\mathrm{a}} \pm 11.21$ & 0.000 & 0.000 & 0.187 \\
EGF, ng/L & $235.7^{\mathrm{b}} \pm 15.03$ & $261.3^{\mathrm{a}} \pm 25.77$ & $276.9^{\mathrm{a}} \pm 16.81$ & $275.0^{\mathrm{a}} \pm 5.56$ & 0.006 & 0.075 & 0.752 \\
& & & & & & &
\end{tabular}

${ }^{a, b, c}$ Means with different superscripts within the same row are statistically different $(P<0.05)$

${ }^{1} \mathrm{PRL}$ : prolactin; IGF-1: insulin-like growth factor-1; EGF: epidermal growth factor

${ }^{2}$ Treatment: CON: control group fed a basal diet without FSBM $(n=5)$; FSBM2: diet with 2\% FSBM $(n=5)$; FSBM4: diet with 4\% FSBM $(n=5)$; FSBM6: diet with 6\% FSBM $(n=4)$

${ }^{3}$ Linear $(\mathrm{L})$, quadratic $(\mathrm{Q})$, or cubic $(\mathrm{C})$ effect of FSBM

Table 5 Effect of isoflavone aglycone-enriched fermented soybean meal (FSBM) on nutrient composition in colostrum and milk of ewes

\begin{tabular}{|c|c|c|c|c|}
\hline \multirow{2}{*}{ Item $^{1}$} & \multicolumn{4}{|c|}{ Treatments $^{2}$} \\
\hline & CON & FSBM2 & FSBM4 & FSBM6 \\
\hline \multicolumn{5}{|c|}{ Colostrum, \% } \\
\hline Fat & $6.36^{c} \pm 0.40$ & $6.80^{b} \pm 0.22$ & $7.20^{a} \pm 0.16$ & $6.79^{b} \pm 0.15$ \\
\hline Protein & $5.46^{b} \pm 0.40$ & $6.08^{a} \pm 0.21$ & $6.22^{a} \pm 0.24$ & $6.01^{a} \pm 0.36$ \\
\hline Lactose & $3.29^{b} \pm 0.24$ & $3.62^{\mathrm{a}} \pm 0.22$ & $3.84^{a} \pm 0.11$ & $3.69^{\mathrm{a}} \pm 0.64$ \\
\hline SNF & $12.96^{\mathrm{b}} \pm 0.10$ & $13.34^{\mathrm{a}} \pm 0.21$ & $13.62^{\mathrm{a}} \pm 0.33$ & $13.34^{\mathrm{a}} \pm 0.15$ \\
\hline \multicolumn{5}{|l|}{ Milk,\% } \\
\hline Fat & $3.73^{b} \pm 0.22$ & $4.48^{\mathrm{a}} \pm 0.32$ & $4.83^{a} \pm 0.16$ & $4.59^{\mathrm{a}} \pm 0.37$ \\
\hline Protein & $3.13^{c} \pm 0.21$ & $3.58^{b} \pm 0.24$ & $4.15^{a} \pm 0.25$ & $3.79^{b} \pm 0.23$ \\
\hline Lactose & $2.99^{b} \pm 0.08$ & $3.39^{a} \pm 0.21$ & $3.44^{a} \pm 0.26$ & $3.35^{a} \pm 0.15$ \\
\hline SNF & $10.08^{b} \pm 0.27$ & $10.32^{b} \pm 0.27$ & $10.76^{a} \pm 0.34$ & $10.45^{b} \pm 0.18$ \\
\hline
\end{tabular}

\footnotetext{
${ }^{a, b, c}$ Means with different superscripts within the same row are statistically different $(P<0.05)$

${ }^{1}$ SNF: non-fat solid

${ }^{2}$ Treatment: CON: control group fed basal diet without FSBM ( $\left.n=5\right)$; FSBM2: diet with 2\% FSBM $(n=5)$; FSBM4: diet with 4\% FSBM ( $n=5)$; FSBM6: diet with 6\% FSBM $(n=4)$

One ewe died because of difficult labour in FSBM6 at parturition
}

The effects of FSBM on immunoglobulin in the colostrum and milk of ewes are presented in Table 6. In both colostrum and milk, compared with CON, feeding ewes with FSBM increased $(P<0.05) \lg$, IgG and IgM concentrations. Furthermore, the concentration of IgG was higher $(P<0.05)$ in FSBM4 and FSBM6 than in FSBM2. 
Table 6 Effects of isoflavone aglycone-enriched fermented soybean meal (FSBM) on concentrations of IgA, IgG and IgM in colostrum and milk of ewes

\begin{tabular}{|c|c|c|c|c|c|c|c|}
\hline \multirow[b]{2}{*}{ Item $^{1}$} & \multicolumn{4}{|c|}{ Treatments $^{2}$} & \multicolumn{3}{|c|}{$P$ value } \\
\hline & CON & FSBM2 & FSBM4 & FSBM6 & $L^{3}$ & $\mathbf{Q}$ & C \\
\hline \multicolumn{8}{|c|}{ Colostrum, $\mu \mathrm{g} / \mathrm{mL}$} \\
\hline $\lg \mathrm{A}$ & $202.3^{b} \pm 18.23$ & $275.5^{a} \pm 15.24$ & $292.3^{a} \pm 17.91$ & $287.0^{a} \pm 15.99$ & 0.000 & 0.000 & 0.322 \\
\hline $\lg G$ & $979.4^{c} \pm 41.31$ & $1126.1^{\mathrm{b}} \pm 53.92$ & $1340.6^{a} \pm 93.76$ & $1278.3^{a} \pm 128.70$ & 0.000 & 0.016 & 0.064 \\
\hline $\lg M$ & $566.6^{b} \pm 49.63$ & $782.1^{a} \pm 23.43$ & $799.6^{a} \pm 56.43$ & $747.0^{\mathrm{a}} \pm 41.92$ & 0.000 & 0.000 & 0.171 \\
\hline \multicolumn{8}{|c|}{ Milk, $\mu \mathrm{g} / \mathrm{mL}$} \\
\hline $\lg A$ & $187.3^{b} \pm 16.07$ & $272.3^{\mathrm{a}} \pm 30.32$ & $290.8^{\mathrm{a}} \pm 21.98$ & $274.5^{\mathrm{a}} \pm 17.98$ & 0.000 & 0.000 & 0.467 \\
\hline $\lg G$ & $976.1^{\mathrm{c}} \pm 35.66$ & $1192.8^{b} \pm 75.30$ & $1321.7^{a} \pm 85.79$ & $1295.0^{\mathrm{a}} \pm 61.54$ & 0.000 & 0.001 & 0.621 \\
\hline $\lg M$ & $559.1^{b} \pm 39.01$ & $744.8^{a} \pm 42.47$ & $757.0^{\mathrm{a}} \pm 54.59$ & $745.0^{a} \pm 44.64$ & 0.000 & 0.000 & 0.118 \\
\hline \multicolumn{8}{|c|}{${ }^{a, b, c}$ Means with different superscripts within the same row are statistically different $(P<0.05)$} \\
\hline \multicolumn{8}{|c|}{$\begin{array}{l}{ }^{1} \text { IgA: immunoglobulin A; IgG: immunoglobulin G; IgM: immunoglobulin M } \\
{ }^{2} \text { Treatment: CON: control group fed a basal diet without FSBM }(n=5) \text {; FSBM2: diet with 2\% FSBM }(n=5) \text {; FSBM4: diet } \\
\text { with 4\% FSBM }(n=5) \text {; FSBM6: diet with } 6 \% \text { FSBM }(n=4)\end{array}$} \\
\hline
\end{tabular}

\section{Discussion}

From late pregnancy to early lactation oxidative stress has been reported both in the mother (Mutinati et al., 2013) and her placenta (Myatt \& Cui, 2004). Excessive ROS production oxidizes the macromolecular lipids, proteins and DNA, leading to organ dysfunction and complicated pregnancy (Trevisan et al., 2001). Previously, in vitro studies on soybean reported that the level of isoflavone aglycone could reach $80 \%$ after fermentation, which exhibited the highest antioxidant activities among the six naturally occurring isoflavones in soybean (Rüfer \& Kulling, 2006; Yang et al., 2013). Isoflavone aglycones (mainly daidzein and genistein) are immediately converted to equol and p-ethyl-phenol in the rumen by microorganisms in cows and ewes, respectively (Lundh, et al., 1990). Equol is reported to have superior antioxidant activity compared with other isoflavones (Setchell et al., 2002). In the current study, the activity of SOD and level of T-AOC were increased in the serum and placenta of FSBM4 and FSBM6. The oxidative injury parameters, 8-OHdG in the placenta and 8-ISO-PGF2 $\alpha$ in the serum, were decreased in FSBM6, suggesting that FSBM supplementation could increase antioxidant capacity and decrease oxidative damage, probably through the production of equol in vivo. Indeed, there are many reports about antioxidants supplementation during pregnancy and lactation in animal husbandry. Zhang et al. (2016) reported that N-carbamylglutamate and rumen-protected L-arginine ameliorated foetal growth restriction, increased the activities of SOD and T-AOC, and decreased MDA concentration both in the maternal and foetal plasma, and placental tissues in underfed ewes. Similarly, glycitein supplementation increased growth performance, enhanced the activities of SOD and T-AOC, and decreased plasma activity of MDA in sows during pregnancy and lactation (Hu et al., 2015). These studies suggest that dietary antioxidant supplementation during pregnancy promotes maternalplacental-foetal health and benefits foetal growth and development by improving antioxidant capacity and preventing oxidative damage. Daidzein and equol are presented mainly as glucuronides rather than aglycones in the tissues of sheep because of the extensive microbial metabolism and conjugation process in the rumen (Urpi-Sarda et al., 2008), which decreased its antioxidant activity (Rimbach et al., 2004). Therefore, further studies are required to verify the production of equol from dietary FSBM supplementation and explore its role and transformation mechanism in ewes.

During the transitional period of pregnancy to lactation, hormones play a crucial role in regulating foetal growth and milk synthesis through integrating environmental signals and nutrient availability (Fowden et al., 2015). Maternal IGF1 concentrations can regulate placental metabolic function and increase nutrient availability to the foetus during gestation, while PRL is able to stimulate maternal IGF production (Handwerger \& Freemark, 2000; Sferruzzi-Perri et al., 2011). EGF was reported to regulate trophoblast proliferation and differentiation in early gestation (Maruo et al., 1992). In the current study, higher concentrations of maternal serum IGF-1 and EGF in FSBM4 and FSBM6 suggested that FSBM could act as an endocrine modulator to increase placental development and function, and benefits the pregnancy 
outcome. Indeed, isoflavones possess an oestrogen hormone function in other tissues. For example, genistein increased EGF and EGF receptor expression in the mammary gland of rats (Brown et al., 1998). Daidzein increased the gene expression of IGF-1 receptor in the skeletal muscle of newborn piglets (Ren et al., 2001). These growth factor systems can initiate mitogen-activated protein kinases and phosphatidylinositol 3-kinase (PI3K)/AKT pathways, which is important for placental function and foetal development (Knöfler, 2010). Further studies are needed to explore whether the MAPK and PI3K/Akt signalling pathways were activated by FSBM supplementation.

Mammary gland development and milk composition play positive roles in the growth and nutrient demand of postnatal lambs. The improvement of fat and lactose in the colostrum and milk composition reflected the positive effect of dietary FSBM doses in the present study. Similar studies in cows indicated that daidzein and genistein increased the proliferation and development of mammary epithelial cells, milk fat and protein, and milk yield (Liu et al., 2012; Liu et al., 2013). Glycitein, another kind of isoflavone, increased the milk protein and fat in sows during late pregnancy and lactation (Hu et al., 2015). The development and maintenance of the mammary gland are dependent on PRL (Santell et al., 1997). The increasing serum PRL in this study was in agreement with the increasing of milk composition. Furthermore, the improvement of milk composition enhances the growth of lambs, and was consistent with the increasing daily gain of litter BW in FSBM6 (Table 2). Therefore, in the current study, the authors believed that FSBM regulates the synthesis of milk fat and protein through improving body condition by regulating the hormones secretion such as PRL and increasing antioxidative capacity (Liu et al., 2013; Hu et al., 2015). On the other hand, fermentation increased active nutrients and their bioavailability, which provide substances for milk synthesis. The nutrient and immunological levels of colostrum and milk are critical for the growth and development of neonates. In the current study, the concentrations of IgA, IgG and IgM in FSBM4 and FSBM6 were higher than those in $\mathrm{CON}$, indicating that the increase of $\operatorname{IgA}$ and $\operatorname{IgM}$ concentrations may be associated with the increase of micromolecular peptides in fermented soybean meal (Feng et al., 2007). Of note, the fat in the colostrum and protein and SNF in the milk were higher in FSBM4 than those in FSBM6. Research has suggested that isoflavone absorption, biotransformation, metabolism and bioavailability depend on factors such as digestive conditions, intestinal transit time and physiological status, especially immunological conditions (WocławekPotocka et al., 2013). Although the serum immunoglobulin levels were not determined, the immunoglobulin in the colostrum and milk between the FSBM4 and FSBM6 groups showed no difference. Therefore, the specific mechanisms need further investigation.

\section{Conclusions}

The current study indicated that, compared with CON and FSBM2, FSBM4 and FSBM6 supplementation increased maternal-placental interface antioxidant capacities, maternal growth factor contents, the nutritional composition and immunoglobulin in the milk of ewes. Considered overall, the level of $4 \%$ supplementation may be recommended. Since small numbers of animals were used in this study, further studies are needed to confirm these results on larger numbers.

\section{Acknowledgements}

This work was supported by the Special Fund for Agro-scientific Research in the Public Interest (No. 201303143); Shanghai Committee of Science and Technology Research Programme (No. 15391912903).

\section{Authors' Contributions}

JX, WX and JZ designed and supervised the experiment; ZL, YZ and SY conducted the experiments and collected the samples; SY performed the sample determination and data analysis; and ZL wrote the manuscript.

\section{Conflict of interest declaration}

No potential conflict of interest was reported by the authors.

\section{References}

Adams, N.R., 1995. Detection of the effects of phytoestrogens on sheep and cattle. J. Anim. Sci. 73, 1509-1515.

AOAC, 1990. Official methods of analysis. Association of Official Analytical Chemists, Arlington, Virginia, USA

Berchieri-Ronchi, C.B., Kim, S.W., Zhao, Y., Correa, C.R., Yeum, K.J. \& Ferreira, A.L.A., 2011. Oxidative stress status of highly prolific sows during gestation and lactation. Anim. 5, 1774-1779.

Brown, N.M., Wang, J., Cotroneo, M.S., Zhao, Y.-X. \& Lamartiniere, C.A., 1998. Prepubertal genistein treatment modulates TGF-a, EGF and EGF-receptor mRNAs and proteins in the rat mammary gland. Mol. Cell. Endocrinol. $144,149-165$.

Castillo, C., Hernandez, J., Bravo, A., Lopez-Alonso, M., Pereira, V. \& Benedito, J.L., 2005. Oxidative status during late pregnancy and early lactation in dairy cows. Vet. J. 169, 286-292.

Champagne, C.P., Tompkins, T.A., Buckley, N.D. \& Green-Johnson, J.M., 2010. Effect of fermentation by pure and mixed cultures of Streptococcus thermophilus and Lactobacillus helveticus on isoflavone and B-vitamin content of a 
fermented soy beverage. Food Microbial. 27, 968-972.

Degen, G.H., Janning, P., Diel, P., Michna, H. \& Bolt, H.M., 2002. Transplacental transfer of the phytoestrogen daidzein in DA/Han rats. Arch. Toxicol. 76, 23-29.

Feng, J., Liu, X., Xu, Z.R., Liu, Y.Y. \& Lu, Y.P., 2007. Effects of Aspergillus oryzae 3.042 fermented soybean meal on growth performance and plasma biochemical parameters in broilers. Anim. Feed Sci. Tech. 134, 235-242.

Fowden, A.L., Forhead, A.J., Sferruzzi-Perri, A.N., Burton, G.J. \& Vaughan, O.R., 2015. Review: Endocrine regulation of placental phenotype. Placenta 36, S50-S59.

Handwerger, S. \& Freemark, M., 2000. The roles of placental growth hormone and placental lactogen in the regulation of human fetal growth and development. J. Pediatr. Endocr. Met. 13, 343-356.

Hu, Y.J., Gao, K.G., Zheng, C.T., Wu, Z.J., Yang, X.F., Wang, L., Ma, X.Y., Zhou, A.G. \& Jiang, Z.J., 2015. Effect of dietary supplementation with glycitein during late pregnancy and lactation on antioxidative indices and performance of primiparous sows. J. Anim. Sci. 93, 2246-2254.

Knöfler, M., 2010. Critical growth factors and signaling pathways controlling human trophoblast invasion. Int. J. Dev. Biol. 54, 269.

Liu, C.L., Li, Z.Q. \& Feng, X.J., 2012. Effects of daidzein or genistein on proliferation and antioxidation of mammary epithelial cell of dairy cow in vitro. Adv. Mater. Res. (Vol. 343, p. 649-654). Trans Tech Publications.

Liu, D.-Y., He, S.J., Jin, E.H., Liu, S.Q., Tang, Y.G., Li, S.H. \& Zhong, L.T., 2013. Effect of daidzein on production performance and serum antioxidative function in late lactation cows under heat stress. Livest. Sci. 152, 16-20.

Lundh, T., 1995. Metabolism of estrogenic isoflavones in domestic animals. P. Soc. Exp. Biol. Med. 208, 33-39.

Lundh, T.J., Pettersson, H.I. \& Martinsson, K.A., 1990. Comparative levels of free and conjugated plant estrogens in blood plasma of sheep and cattle fed estrogenic silage. J. Agr. Food Chem. 38, 1530-1534.

Luo, Z., Zhu, W., Guo, Q., Luo, W., Zhang, J., Xu, W. \& Xu, J., 2016. Weaning induced hepatic oxidative stress, apoptosis, and aminotransferases through MAPK signaling pathways in piglets. Oxid. Med. Cell. Longev. 2016, 4768541.

Maruo, T., Matsuo, H., Murata, K. \& Mochizuki, M., 1992. Gestational age-dependent dual action of epidermal growth factor on human placenta early in gestation. J. Clin. Endocr. Metab. 75, 1362-1367.

Min, J., Park, B., Kim, Y.J., Lee, H., Ha, E. \& Park, H., 2009. Effect of oxidative stress on birth sizes: consideration of window from mid pregnancy to delivery. Placenta 30, 418-423.

Murakami, H., Asakawa, T., Terao, J. \& Matsushita, S., 1984. Antioxidative stability of tempeh and liberation of isoflavones by fermentation. Agr. Biol. Chem. 48, 2971-2975.

Mutinati, M., Piccinno, M., Roncetti, M., Campanile, D., Rizzo, A. \& Sciorsci, R.L., 2013. Oxidative stress during pregnancy in sheep. Reprod. Domest. Anim. 48, 353-357.

Myatt, L. \& Cui, X., 2004. Oxidative stress in the placenta. Histochem. Cell Biol. 122, 369-382.

Ren, M.Q., Kuhn, G., Wegner, J., Nurnberg, G., Chen, J. \& Ender, K., 2001. Feeding daidzein to late pregnant sows influences the estrogen receptor beta and type 1 insulin-like growth factor receptor mRNA expression in newborn piglets. J. Endocrinol. 170, 129-135.

Rimbach, G., Weinberg, P.D., de Pascual-Teresa, S., Alonso, M.G., Ewins, B.A., Turner, R., Minihane, A.M., Botting, N., Fairley, B., Uchida, Y. \& Cassidy, A., 2004. Sulfation of genistein alters its antioxidant properties and its effect on platelet aggregation and monocyte and endothelial function. BBA-Gen. Subjects 1670, 229-237.

Ruiz-Larrea, M.B., Mohan, A.R., Paganga, G., Miller, N.J., Bolwell, G.P. \& Rice-Evans, C.A., 1997. Antioxidant activity of phytoestrogenic isoflavones. Free Radical Res. 26, 63-70.

Rüfer, C.E. \& Kulling, S.E., 2006. Antioxidant activity of isoflavones and their major metabolites using different in vitro assays. J. Agr. Food Chem. 54, 2926-2931.

Santell, R.C., Chang, Y.C., Nair, M.G. \& Helferich, W.G., 1997. Dietary genistein exerts estrogenic effects upon the uterus, mammary gland and the hypothalamic/pituitary axis in rats. J. Nutr. 127, 263-269.

Setchell, K.D., Brown, N.M. \& Lydekingolsen, E., 2002. The clinical importance of the metabolite equol-a clue to the effectiveness of soy and its isoflavones. J. Nutr. 132, 3577-84.

Sferruzzi-Perri, A.N. \& Camm, E.J., 2016. The programming power of the placenta. Front. Physiol. 7.

Sferruzzi-Perri, A.N., Owens, J.A., Pringle, K.G. \& Roberts, C.T., 2011. The neglected role of insulin-like growth factors in the maternal circulation regulating fetal growth. J. Physiol. 589, 7-20.

Sugino, N., Takiguchi, S., Umekawa, T., Heazell, A. \& Caniggia, I., 2007. Oxidative stress and pregnancy outcome: A workshop report. Placenta 28, S48-S50.

Taponen, J., Mustonen, E.A., Kontio, L., Saastamoinen, I., Vanhatalo, A., Saloniemi, H. \& Wähälä, K., 2010. Red clover derived isoflavones: Metabolism and physiological effects in cattle and sheep and their concentration in milk produced for human consumption. Recent Adv. Poly. Res. 2, 238-254.

Trevisan, M., Browne, R., Ram, M., Muti, P., Freudenheim, J., Carosella, A.M. \& Armstrong, D., 2001. Correlates of markers of oxidative status in the general population. Am. J, Epidemiol. 154, 348-356.

Urpi-Sarda, M., Morand, C., Besson, C., Kraft, G., Viala, D., Scalbert, A., Besle, J.M. \& Manach, C., 2008. Tissue distribution of isoflavones in ewes after consumption of red clover silage. Arch. Biochem. Biophys. 476, 205-210.

Wocławek-potocka, I., Mannelli, C., Boruszewska, D., Kowalczykzieba, I., Waśniewski, T. \& Skarżyński, D.J., 2013. Diverse effects of phytoestrogens on the reproductive performance: cow as a model. Int. J. Endocrinol. 2013, 650984.

Xu, J., Yang, S., Bao, J. \& Sheng, Y., 2014. The method of improved efficiency of transformation of soybean isoflavone by compound probiotics fermentation. China patent $201,310,557,000$.

Yang, S. \& Xu, J., 2013. Biotransformation of soybean isoflavone by microbial solid-state fermentation. Mod. Food Sci. Technol. 29, 1867-1871. 
Yin, X., Ding, R., Cai, X., Fang, H. \& Xu, J., 2015. Research of antioxidant capacity by the soybean meals fermented with high reactive soybean isoflavones. Biotechnology 25, 296-30.

Yu, S., Shi, D., Zhu, Y., Xu, J., Xu, W. \& Zhang, J., 2017. A research in oxidative stress and damage of breeding goats. Chinese J. Nutr. 29, 814-823.

Yuan, J., Wang, J. \& Liu, X., 2007. Metabolism of dietary soy isoflavones to equol by human intestinal microflora implications for health. Mol. Nutr. Food Res. 51, 765-781.

Zhang, H., Sun, L., Wang, Z., Deng, M., Nie, H., Zhang, G., Ma, T. \& Wang, F., 2016. N-carbamylglutamate and L-arginine improved maternal and placental development in underfed ewes. Reproduction 151, 623-635. 